\section{Case Reports in Ophthalmology}

Case Rep Ophthalmol 2017;8:390-395

DOI: $10.1159 / 000478720$ Published online: July 24, 2017
(C) 2017 The Author(s)

Published by S. Karger AG, Basel www.karger.com/cop

This article is licensed under the Creative Commons Attribution-NonCommercial 4.0 International License (CC BY-NC) (http://www.karger.com/Services/OpenAccessLicense). Usage and distribution for commercial purposes requires written permission.

\title{
Ruptured Retinal Arterial Macroaneurysm Secondary to Toxoplasmic Kyrieleis Arteriolitis: A Case Report
}

\author{
Natalie Huang ${ }^{a}$ c $\quad$ W. Andrew Lee ${ }^{b} \quad$ Sean Rivera ${ }^{c}$ \\ Sandra R. Montezumac \\ ${ }^{a}$ Oakland University William Beaumont School of Medicine, Rochester, MI, USA; \\ ${ }^{\mathrm{b}}$ University of Minnesota Medical School, Minneapolis, MN, USA; 'Department of \\ Ophthalmology and Visual Neurosciences, University of Minnesota, \\ Minneapolis, MN, USA
}

\section{Keywords}

Ocular toxoplasmosis · Retinal arterial macroaneurysm · Kyrieleis arteriolitis

\begin{abstract}
Purpose: The aim of this report was to describe multimodal ocular imaging findings in a patient who presented with a ruptured retinal arterial macroaneurysm (RAM) associated with toxoplasmic Kyrieleis arteriolitis. Methods: We report the case of a 64-year-old man with a history of systemic hypertension and dense amblyopia of the left eye who presented with decreased vision and new floaters in the left eye. Color fundus photography, spectral-domain optical coherence tomography, fluorescein angiography, and indocyanine green angiography were used as diagnostic imaging tools. Results: No signs of hypertensive retinopathy were noted in the right eye. Multiple chorioretinal scars characteristic of previous toxoplasmosis were revealed in the left eye, with one covering most of the macula. Periarterial plaques or Kyrieleis arteriolitis were observed in retinal arteries surrounding the toxoplasmic retinal scars. Multiple RAMs were observed in these vessels, one of which was acutely ruptured. A perivenular plaque associated with a chronic branch retinal vein occlusion (BRVO) was noted along the same arcade at the arteriovenous crossing. Conclusion: RAM formation and BRVO
\end{abstract}




\section{Case Reports in Ophthalmology}

\begin{tabular}{l|l}
\hline DOI: $10.1159 / 000478720$ & C 2017 The Author(s). Published by S. Karger AG, Basel \\
\hline
\end{tabular} www.karger.com/cop

Huang et al.: Ruptured Retinal Arterial Macroaneurysm Secondary to Toxoplasmic Kyrieleis Arteriolitis: A Case Report

can present as possible long-term complications of toxoplasmic Kyrieleis arteriolitis. This is the first reported case demonstrating an association between toxoplasmic Kyrieleis arteriolitis and RAM formation.

(C) 2017 The Author(s)

Published by S. Karger AG, Basel

\section{Introduction}

Toxoplasmic retinitis has been reported to cause periarterial plaques, also known as Kyrieleis arteriolitis [1]. There have been no reported cases of retinal arterial macroaneurysm (RAM) associated with Kyrieleis arteriolitis. In this case report, we present a patient with a ruptured RAM in the setting of Kyrieleis arteriolitis.

\section{Case Report}

A 64-year-old male presented with a 4-day history of new floaters and decreased vision in the left eye. His past medical history was significant for systemic hypertension and dense amblyopia of the left eye, likely due to toxoplasmic macular scarring. On physical exam, visual acuity was 20/20 in the right eye and 20/300 in the left eye. Intraocular pressures were normal. Pupils were normal with no afferent pupillary defect. Extraocular movements were full with a large-angle exotropia of the left eye. On fundus exam, the right eye had a normal fundus with no signs of hypertensive retinopathy (Fig. 1a). Fig. 1b is a color fundus photograph of the left eye, which revealed a large variably pigmented chorioretinal lesion covering almost the entire macula, consistent with an inactive toxoplasmic scar. Multilevel retinal hemorrhage consistent with RAM can be observed. There was moderate vitreous hemorrhage, mostly inferiorly settled. Preretinal hemorrhage superior to the optic nerve and preretinal, retinal, and subretinal hemorrhages adjacent to the macular scar were noted. A second small chorioretinal scar adjacent to the superotemporal arcade was observed on the color fundus photograph. The superotemporal arcade vessels showed significant attenuation with periarterial plaques, consistent with old toxoplasmic Kyrieleis arteriolitis (Fig. 1b). Both fundus fluorescein angiography (FA) and indocyanine green angiography (ICGA) (Fig. $2 \mathrm{a}, \mathrm{b}$ ) of the right eye showed normal retinochoroidal vasculature. Figure $3 \mathrm{a}$ illustrates the late phase of the FA of the left eye, which demonstrated a homogeneously hypofluorescent masking lesion contiguous to the macular scar, congruous with preretinal hemorrhage. Three hyperfluorescent RAMs were detected in the vessels feeding the retinal scars, with a prominent one located at the center of the masking lesion, which is most likely the site of rupture. Besides the 2 toxoplasmic retinal scars seen on fundus photography, FA revealed a third large chorioretinal hypofluorescent scar located in the superotemporal mid-periphery. Both large retinal scars were hypofluorescent with hyperfluorescent margins. In addition, there were multiple microaneurysms located superior to the macular scar and along the superotemporal arcade, as well as retinal capillary nonperfusion and retinal collaterals adjacent to the mid-peripheral chorioretinal scar, likely resulted from chronic branch retinal venous occlusion at the arteriovenous crossing (Fig. 3a). On ICGA, as demonstrated in Figure $3 \mathrm{~b}$, vessels around the chorioretinal scars were attenuated, with no evidence of leaking or active vasculitis, and the same RAMs seen on FA were also evident. As shown in Figure 4a-c, the spectral-domain optical coherence tomography revealed hyperreflective preretinal and subretinal lesions adjacent to a hyperreflective atrophied macular scar, consistent with preretinal and subretinal hemorrhages. 
Considering that this patient did not have an active toxoplasmosis, active vasculitis, or significant macular edema and the history of dense amblyopia due to the macular scarring, we decided to manage his ruptured RAM expectantly. The patient's symptoms remained stable with gradual resolution of the vitreous hemorrhage at the 1-week return visit. His visual acuity returned to baseline within several months. Unfortunately, the patient was lost to follow-up afterwards.

\section{Discussion}

Ocular toxoplasmosis is a common cause of significant visual loss in the youth population [2]. Congenital ocular toxoplasmosis is more likely than acquired infection to be bilateral [2]. Acute acquired ocular toxoplasmosis can present at any age and has a predilection for presenting with larger lesions [3]. It is known that most RAMs are associated with aging of the vessel walls and cardiovascular diseases, such as systemic hypertension, arterial emboli, and arteriosclerosis [4, 5]. Toxoplasmosis retinitis has been reported to cause periarterial plaques, also known as Kyrieleis arteriolitis (Fig. 1b), which could induce arterial emboli [1]. Therefore, we propose that the mechanism of multiple RAM formation in our patient was likely a sequela of retinal arterial emboli triggered by toxoplasma vasculitis. In addition, this process could have been aggravated by the patient's history of hypertension. However, fundus examination, FA, and ICGA of the fellow eye did not reveal signs of hypertensive retinopathy (Fig. 1a, Fig. 2a, b). Therefore, the extent to which systemic hypertension contributed to the formation of the macroaneurysm is limited, further suggesting that old toxoplasmic vasculitis played a role. In addition, branch retinal vein occlusion (BRVO) has been reported to be associated with retinal toxoplasmosis [6, 7]. A chronic BRVO along with its complications - formation of microaneurysms, retinal capillary nonperfusion, and retinal collaterals is also present in our patient (Fig. 3a).

Traditionally, when toxoplasmosis is active and involving the macula, triple therapy (pyrimethamine, sulfadiazine, and prednisone) has been used [8]. This patient did not have active disease, so triple therapy was not considered. Visual outcome for ruptured RAM is favorable $[9,10]$. Treatment options for ruptured RAM include observation, focal laser coagulation, and intravitreal bevacizumab for secondary macular edema [9-14]. Observation is sufficient in some uncomplicated cases, as aneurysmal hemorrhaging usually spontaneously undergoes sclerosis and occlusion as part of its natural course [10]. Conventional laser photocoagulation of the macroaneurysm has been the most commonly utilized treatment for symptomatic RAM; however, it may carry the risk of an increased rate of arterial occlusion, capillary dropout, subretinal fibrosis, enlargement of laser scar, and choroidal neovascularization compared to nontreatment [10-14]. A recent clinical trial suggests that subthreshold laser treatment may carry fewer risks [12]. Intravitreal bevacizumab has been shown to be an effective treatment for improving visual acuity in patients with complicated RAM involving the fovea [14].

\section{Conclusion}

We conclude that RAM formation and chronic BRVO could present as long-term sequelae of vasculitis in the context of toxoplasmic retinitis. To our knowledge, this is the first case in the literature describing an association between Kyrieleis arteriolitis and RAM formation. 
Huang et al:: Ruptured Retinal Arterial Macroaneurysm Secondary to Toxoplasmic Kyrieleis Arteriolitis: A Case Report

\section{Statement of Ethics}

The patient discussed in this case report provided written informed consent; authorization for publication was provided.

\section{Disclosure Statement}

The authors declare no conflicts of interest.

\section{References}

1 Agarwal A: Infectious diseases of the retina and choroid; in Agarwal A (ed): Gass' Atlas of Macular Diseases, ed 5. Philadelphia, PA, Saunders, 2013, pp 850-854.

-2 Atmaca LS, Simsek T, Batioglu F: Clinical features and prognosis in ocular toxoplasmosis. Jpn J of Ophthalmol 2004;48:386-391.

3 Delair E, Latkany P, Noble AG, Rabiah P, McLeod R, Brézin A: Clinical manifestations of ocular toxoplasmosis. Ocul Immunol Inflamm 2011;19:91-102.

-4 Panton RW, Goldberg MF, Farber MD: Retinal arterial macroaneurysms: risk factors and natural history. Br J Ophthalmol 1990;74:595.

5 Chew EY, Murphy R: Acquired retinal macroaneurysms; in Ryan SJ (ed): Retina, ed 5. London, Saunders/Elsevier, 2013, pp 1026-1028.

-6 Kouros P, Gerding H: Retinochoroiditis toxoplasmotica initially presenting as branch retinal vein occlusion. Klin Monatsbl Augenheilkd 2015;232:573-575.

7 Aggio FB, Novelli FJ, Rosa EL, Nobrega MJ: Combined branch retinal vein and artery occlusion in toxoplasmosis. Arq Bras Oftalmol 2016;79:189-191.

-8 Soheilian M, Ramezani A, Azimzadeh A, Azimzadeh A, Mehdi Sadoughi M, Dehghan MH, Shahghadami R, Yaseri M, Peyman GA: Randomized trial of intravitreal clindamycin and dexamethasone versus pyrimethamine, sulfadiazine, and prednisolone in treatment of ocular toxoplasmosis. Ophthalmology 2011;118:134-141.

-9 Koinzer S, Heckmann J, Tode J, Roider J: Long-term, therapy-related visual outcome of 49 cases with retinal arterial macroaneurysm: a case series and literature review. Br J Ophthalmol 2015;99:13451353.

10 Brown DM, Sobol WM, Folk JC, Weingeist TA: Retinal arteriolar macroaneurysms: long-term visual outcome. Br J Ophthalmol 1994;78:534-538.

11 Panton RW, Goldberg MF, Farber MD: Retinal arterial macroaneurysms: risk factors and natural history. Br J Ophthalmol 1990;74:595.

12 Battaglia Parodi M, Iacono P, Pierro L, Papayannis A, Kontadakis S, Bandello FM: Subthreshold laser treatment versus laser treatment for symptomatic retinal arterial macroaneurysms. Invest Ophthalmol Vis Sci 2012;53:1783-1786.

-13 Pieramici DJ, Risard SM, Rabena MD: Retinal neovascularization associated with a retinal arterial macroaneurysm. Retin Cases Brief Rep 2009;3:415.

14 Pichi F, Morara M, Torrazza C, Manzi G, Alkabes M, Balducci N, Vitale L, Lembo A, Ciardella A, Nucci P: Intravitreal bevacizumab for macular complications from retinal arterial macroaneurysms. Am J Ophthalmol 2013;155:287-294. 


\section{Case Reports in Ophthalmology}
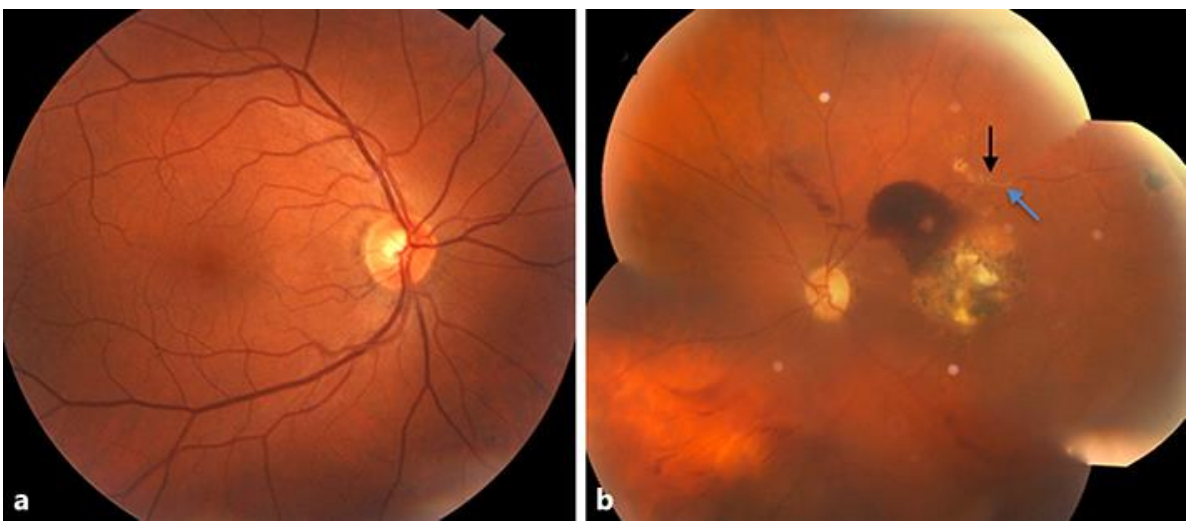

Fig. 1. a Color fundus photograph of the right eye shows a normal fundus. b Color fundus photograph of the left eye demonstrates retinal multilevel hemorrhage adjacent to a variably pigmented macular toxoplasmic scar. Black arrow, Kyrieleis arteriolitis with retinal artery plaque; blue arrow, perivenular plaque.
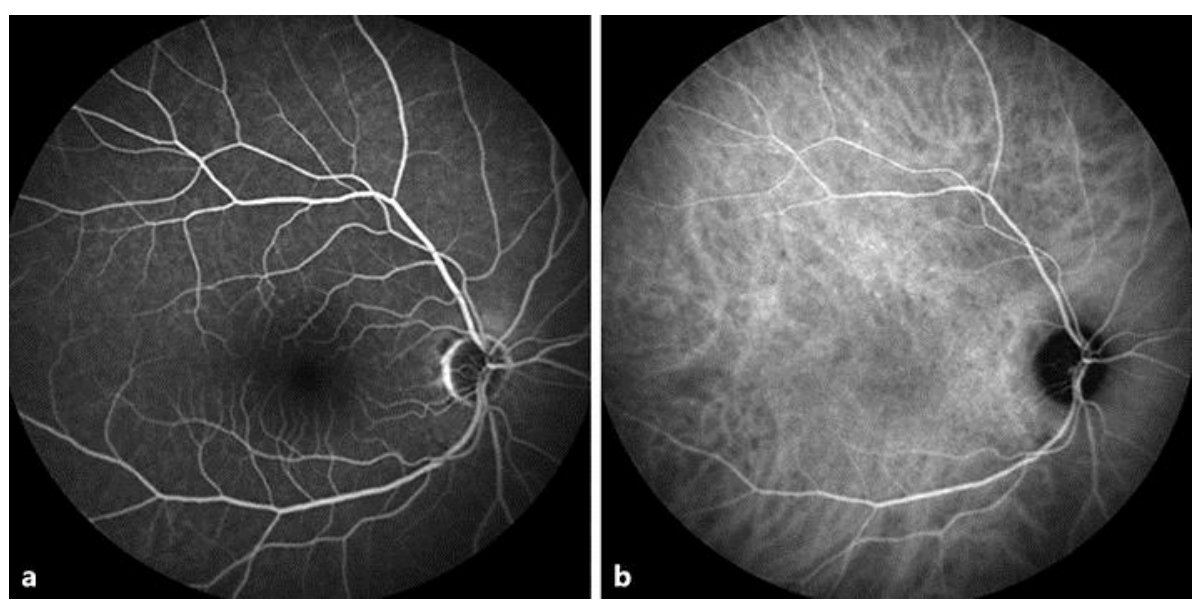

Fig. 2. Fundus fluorescein angiography (a) and indocyanine green angiography (b) of the right eye show normal retinal and choroidal vessels. 


\section{Case Reports in Ophthalmology}
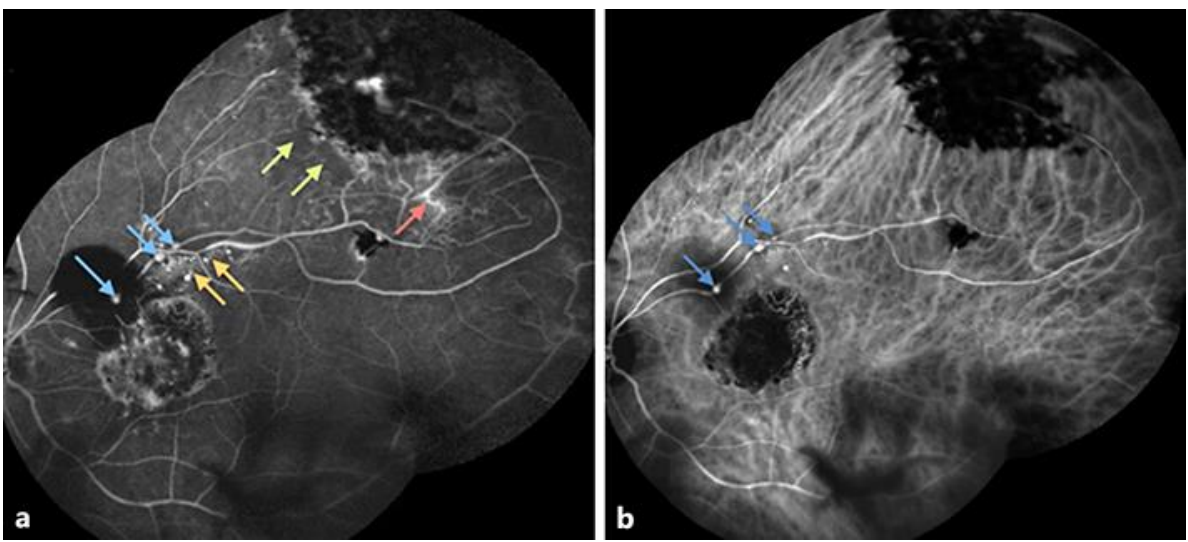

Fig. 3. a Fundus fluorescein angiography of the left eye illustrates 3 hypofluorescent chorioretinal scars with hyperfluorescent margins in the macula and along the superotemporal arcade and superotemporal mid-periphery, respectively. b Indocyanine green angiography of the left eye highlights the same 3 chorioretinal scars. Blue arrows, retinal arterial macroaneurysms; orange arrows, retinal arterial microaneurysms; green arrows, retinal capillary nonperfusion; red arrow, retinal collaterals.
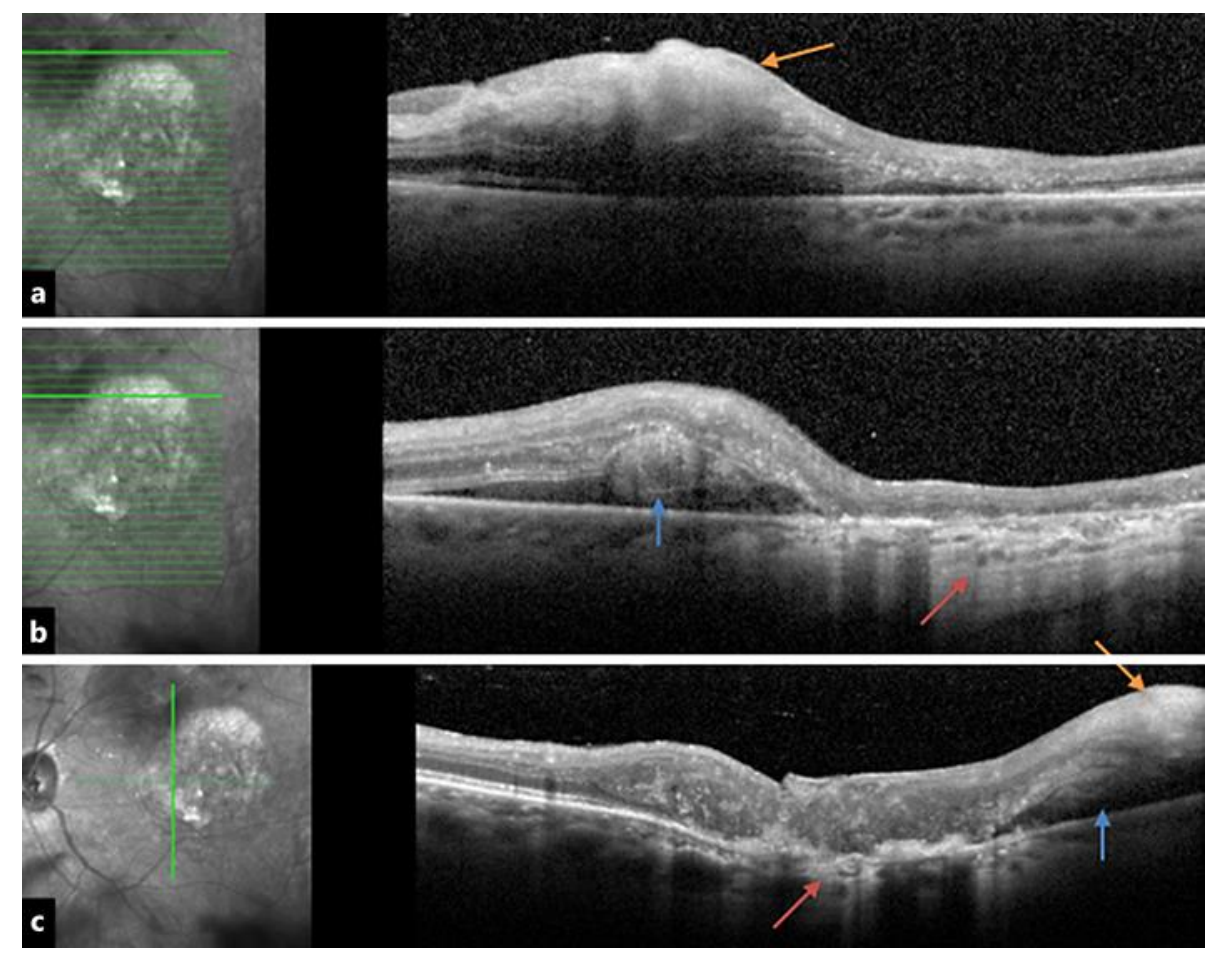

Fig. 4. a Spectral-domain optical coherence tomography (SD OCT) of the retina with a hyperreflective preretinal hemorrhage over the site of a ruptured retinal arterial macroaneurysm. b SD OCT of the retina with a hyperreflective subretinal hemorrhage adjacent to the atrophied macular scar. c Vertical SD OCT of the retina shows both preretinal and subretinal hemorrhages adjacent to the macular scar. Blue arrows, subretinal hemorrhage; orange arrows, preretinal hemorrhage; red arrows, macular scar. 